\author{
Marquette University \\ e-Publications@Marquette
}

Languages, Literatures and Culture Faculty

Research and Publications

2022

\title{
Experiences of Muslim Mothers of Children with Disabilities: A Qualitative Study
}

\author{
Enaya Othman \\ Marquette University, enaya.othman@marquette.edu \\ Lee Za Ong \\ Marquette University, leeza.ong@marquette.edu \\ Irfan A. Omar \\ Marquette University, irfan.omar@marquette.edu \\ Abir K. Bekhet \\ Marquette University, abir.bekhet@marquette.edu \\ Janan Najeeb \\ Milwaukee Muslim Women's Coalition
}

Follow this and additional works at: https://epublications.marquette.edu/arabic

Part of the Arabic Language and Literature Commons

\section{Recommended Citation}

Othman, Enaya; Ong, Lee Za; Omar, Irfan A.; Bekhet, Abir K.; and Najeeb, Janan, "Experiences of Muslim Mothers of Children with Disabilities: A Qualitative Study" (2022). Arabic Languages and Literatures. 9. https://epublications.marquette.edu/arabic/9 


\section{Experiences of Muslim Mothers of Children with Disabilities: A Qualitative Study}

\begin{tabular}{|r|l|}
\hline Journal: & Journal of Disability \& Religion \\
\hline Manuscript ID & WRDH-2020-0038.R1 \\
\hline Keywords: & Disability, Islam, Mental Health, Inclusion, Parent \\
\hline Abstract: & $\begin{array}{l}\text { The purpose of this study is to explore the experiences of Muslim } \\
\text { mothers of children with disabilities. Many studies have addressed the } \\
\text { challenges faced by family caregivers in Western societal settings and } \\
\text { little is known about the challenges of Muslim mothers of children with } \\
\text { several themes regarding the values in caregiving, disparity, fortitude, } \\
\text { and needs. It provided a unique perspective on the intersection of } \\
\text { gender with culture, religion, and immigrant status for the caregivers. } \\
\text { The implication on the cultural stigmatization of disability in Muslim } \\
\text { communities is discussed. }\end{array}$ \\
\hline
\end{tabular}





\begin{abstract}
The purpose of this study is to explore the experiences of Muslim mothers of children with disabilities. Many studies have addressed the challenges faced by family caregivers in Western societal settings and little is known about the challenges of Muslim mothers of children with disabilities faced and the impact to their well-being. The study revealed several themes regarding the caregiver sentiments, disparity, fortitude, and needs. It provided a unique perspective on the intersection of gender with culture, religion, and immigrant status for the caregivers. The implication on the cultural stigmatization of disability in Muslim communities is discussed.
\end{abstract}

Keywords: disability, Muslims, gendered stigma, intersectionality, caregivers, mother 


\section{Experiences of Muslim Mothers of Children with Disabilities: A Qualitative Study}

Having a family member with a disability is a complex situation for family caregivers. Many studies have addressed the challenges faced by family caregivers in Western societal settings. The research included caregivers' perspective on barriers and resilience (Saria et al., 2017), caregivers' quality of life and mental health (Hooda \& Gupta, 2017), caregiver burden (Kayadjanian et al., 2018; Koehler et al., 2014; Wiener et al., 2016), stress reduction intervention for caregivers (Bazzano et al., 2015), outcome research (Williamson \& Perkins, 2014), and female caregivers' mental health issues (Pinquart \& Sorensen, 2006). However, there is limited research investigating the experience of caregivers from diverse cultural backgrounds in the United States, and particularly female Muslim caregivers and Muslim mothers of children with disabilities as proposed in this study. Although in Islam, disability is not seen as a divine punishment, research shows that it is often perceived as one in many Muslim communities (Aloud, \& Rathur 2009; Ciftci \& Jones \& Corrigan, 2013). Mothers are often at the center of this predicament as they have been traditionally responsible for the caregiving roles; and yet, little is known about the impact of these challenges on their experience and well-being. The purpose of this study is to explore the experiences of Muslim mothers of children with disabilities. A descriptive, exploratory and qualitative approach was employed to acquire useful insight into the unique experiences of participants and their well-being. More specifically, this study examines the needs and experiences of Muslim mothers of children with disability from a multi-layered perspective, incorporating psychological research and cultural analysis in order to uncover how health intersects with culture, religion, and gender. This study is significant not only because it provides culturally responsive information for Muslim clergy and religious leaders, social service professionals, and allied health professionals to improve their services to this community, it also 
aims to contribute to further thinking on how to end the cultural stigmatization of disability in Muslim communities. This study demonstrates the acute need to inform and educate the public as many mothers reported that they have had to deal with negative perceptions and lack of support in the community. Another significance of this study lies in its interdisciplinary scope bringing together research modalities belonging to social sciences and humanities.

\section{Background and Significance}

Research has shown evidence regarding the effects of sociocultural factors and perspectives on the family caring experience and roles. For caregiving experience, immigrants often express disappointment with the services that are offered and the lack of access to substantial relevant resources. They are faced with the difficulty of making sense of disability while confronted with stigma. They report feeling uncertain about action and are overwhelmed by the challenges they face (Heer et al., 2012; Heer, Larkin, \& Rose, 2015; Neufeld et al., 2002). The mothers in Muslims communities reported living with anxiety, depression, uncertainty, and distress when caring for their children (Nahal et al., 2017; Ahmad \& Khan, 2018). In terms of caregiving roles, the study has shown that Muslim mothers are prominently involved in the caregiving role when there is a child or a husband with a disability in the family. In many Muslim cultures a strong emphasis is placed on family values which are often rooted in patriarchal practices. Under such social systems, the mothers are more likely to be perceived as caregivers which becomes their primary role in the family and community (Neufeld et al., 2002; Williamson \& Perkins, 2014). Out of a sense of love, spiritual fulfillment, a sense of duty, guilt, and social pressures, mothers have come to play an important role in the family as unpaid, informal caregivers (Ahmad \& Khan, 2018; Nadal et al., 2015). They have been determined to be generally responsible for meeting the physical and psychological needs of the dependent. 
These responsibilities can range from (a) performing the practical tasks such as shopping, cooking, bathing, feeding; (b) carrying out case management tasks such as coordinating doctor appointments, supporting medication adherence, treatment expenses, treatment monitoring, accessing education resources, and (c) providing emotional support such as listening and managing anxiety and fears of the person with disabilities (Ahmad \& Khan, 2018).

The informal care that is provided by the mother in the household is effective but can also have some implications and challenges in terms of their caregiving experience. Muslim communities share the same hidden social and psychological implications such as mental health concerns and lack of social engagement of those who care for individuals with disabilities (Wiener et al., 2016; Williamson \& Perkins, 2014). Although caregivers of children with disabilities are essential in the process of recovery and managing the medical conditions of their children, the caregivers themselves frequently experience high levels of anguish that impacts their mental health and general well-being (Ahmad \& Khan, 2018; Mathias et al., 2019). In terms of gendered differences, Mathias et al (2019) reported that female caregivers in the family experience higher levels of stress when engaging in caregiving activities. The caregiving endeavor had a long-term effect on their self-esteem, hope for the future, social engagement, and emotional well-being (Ahmad \& Khan, 2018; Heer et al., 2015; Mathias et al., 2019). Moreover, theoretically speaking, there are three areas that caregivers were confronted with: emotions, actions, and external force (Miller et al., 2017). Their feelings of frustration, being burdened, not receiving help, and perceived lack of options impact their advocacy for better access to services (Miller et al., 2017).

While many female caregivers encounter obstacles related to disability issues, the Islamic religious texts (the Qur'an and the Hadith) and other scholarly sources address the issue of 
disability in positive ways stressing that no blame should ever be assigned to anyone for being disabled (Qur'an 48:17a). These sources stress that individuals with disabilities and their caregivers should be treated with kindness and respect (Conway, 2014; Reinhart, 2005). Further, the religious sources also note examples of how to address the needs of someone who lives with disability and requires assistance (Conway, 2014; Reinhart, 2005). Among the types of assistance that may be available, the role of caregiver is highlighted in early Muslim history (AlAoufi, Al-Zyoud, and Shahminan, 2012). Thus, religiously and ethically speaking, in Islam, disability has been regarded as a positive condition where a person who needs some form of assistance is no less than another person, and where his or her abilities and skills should not be used to define that person (Reinhart, 2005). Similarly, the role of a caregiver is sanctified in Muslim sources as it relates to the notion of service to others, which is both a virtue ethic and an applied ethic in Islam. The first speaks to the moral character of the agent serving others while the second values consequences of service aimed at the well-being of those served (Conway, 2014; Reinhart, 2005).

In reality, a family who has a child or children with disabilities continue to experience challenges in equal access to resources as well as moral and social support (Al-Krenawi, Graham, \& Al-Gharaibet, 2011; Haskell et al., 2016). Cultural context appears to be the main factor in determining whether or not there is stigma attached to disability. (Al-Aoufi, Al-Zyoud, and Shahminan, 2012). The current study addresses such challenges experienced by female caregivers in the context of Muslim communities in the United States. This study contributes to the subject by examining other dimensions of the lives of caregivers; their immigrant or refugee experience, religious beliefs, types of stigma faced at religious or cultural organizations, and gender roles within the family. 
It is evident that previous studies have examined the experiences of Muslim female caregivers and its impact towards their well-being, globally. While cultural and religious perceptions of disability extensively shape the way individuals or families cope with disability, the imposition on women and implications of gender roles further complicate whether they receive services or not. However, the research exclusively focused on experiences of Muslim mothers in their own countries such as Saudi Arabia (Mohamed Madi, Mandy, \& Aranda, 2019), Turkey (Diken, 2006), and Palestine (Nahal, Wigert, Wigert, \& Axelsson, 2017). There is a lack of applied research on the Muslim female caregivers of their loved ones with disabilities in the United States. Muslim immigrants and Muslim Americans generally experience discrimination and Islamophobia due to factors such as having a minority status and being an immigrant (AbuRas, Suarez, \& Abu-Bader, 2018). Particularly, being a Muslim American woman makes one even more vulnerable due to their religious minority status, race, ethnicity, and/or ancestral origin. These factors can further increase the likelihood of them experiencing discrimination and stigma in the United States. There is a strong relationship between stigma, abuse, and depression among Muslim women (Budhwani \& Hearld, 2017). Furthermore, the intersectionality of being a woman, a Muslim, and with a disability particularly exhibited a wide range of challenges that could affect individuals' well-being (Abu-Ras et al., 2018; Nadal et al., 2015). In terms of research designs, there are only a few that used qualitative methods to elicit deeper understanding of their unique caregiving experience (del Rio Lozano et al., 2013; Pharr et al., 2014; Swaine et al., 2013). Research related to the experience of caregivers of individuals with disabilities in the United States has been primarily quantitative and focusing on mainstream caregivers' perspective on barriers and resilience (Saria et al., 2017), caregivers' quality of life and mental health (Hooda \& Gupta, 2017; Litzelman et al., 2014), caregiver burden 
(Kayadjanian et al., 2018; Koehler et al., 2014; Wiener et al., 2016), stress reduction intervention for caregivers (Bazzano et al., 2015), outcome research (Williamson \& Perkins, 2014), and female caregivers' mental health issues (Pinquart \& Sorensen, 2006). This study attempted to investigate the experiences of Muslim mothers of children with disabilities in the United States. Considering the lack of social science/psychology/feminist literature on this population in the United States, qualitative approach is employed to illuminate their unique experiences to provide useful insight into the barrier, challenges and strengths (Houser, 2019).

\section{Methods}

\section{Participants}

Participants were 11 Muslim mothers of children with disabilities from the Midwest region of the U.S. According to the Family Caregiver Alliance (2019), approximately 43.5 million caregivers have provided unpaid care to an adult or child in the last 12 months, $14 \%$ of them care for a child and female caregivers spend more time providing care (Family Caregiver Alliance, 2019). Although there are estimates of the Muslim population in the U.S. (1.1\% of the total United States. population according to Mohamed, 2018), there is no data specifically on Muslim mothers of children with disabilities. The participants in this study were all mothers who identified themselves as Muslims and reported being the main informal caregivers of their children at home.

Due to the small Muslim community in the Midwest region and the social stigma of having a family member with a disability, the reports of the demographic characteristics were kept in general to protect their privacy. The participants ranged in age from 33 to $64(M=49, S D$ $=10.78)$. Most are married (90\%), first-generation immigrants $(80 \%)$, have a family member that is 18 years and older with a disability $(81 \%)$, have associate degree and/or higher education level 
(91\%), and work full time (64\%) (insert Table 1). Majority of the individuals with disability that the participants care for are adult $(75 \%)$, with difficulty in the mental domain such as intellectual disability, depression, anxiety, autism, or other mental or emotional conditions that seriously interfered with everyday activities (insert Table 2).

\section{Design}

To fulfill the purpose of tapping into the in-depth experience of Muslim mothers of children with disabilities in the U. S., an exploratory and descriptive qualitative research design is used to investigate the in-depth lived experience of the participants. Exploratory and descriptive qualitative research design has been identified as important and appropriate for research that focused on discovering the details of experiences and gaining insights from marginalized participants' phenomenon (Kim, Sefcik, \& Bradway, 2017). The qualitative design also aimed to investigate the intersectionality of culture, gender, and experiences of caregivers.

\section{Researchers}

All the authors are the first-generation immigrants from different Muslim countries. The first author is a first-generation immigrant from Palestine. She is the founder of Arab and Muslim Women's Research and Resource Institute, AMWRRI and she serves as the President of AMWRRI Board of Directors. Her research focuses on women's identities, gender power relations, and body politics and gendered disability, particularly in the contexts of cultural encounter. The second author is a first-generation immigrant from Malaysia. Her research interests are rehabilitation counseling issues, multicultural counseling, refugees/immigrants with disabilities, and curriculum evaluation. The third author is a first-generation immigrant from India and specializes in Islamic thought with a special focus on inter-religious connections between Islam and other religions. The fourth author is a first-generation immigrant and has 
research interests that include effects of positive cognitions, resourcefulness, and resilience in overcoming adversity in vulnerable populations. The fifth author is a founding member and the current President of the Milwaukee Muslim Women's Coalition (MMWC). She has been an active spokeswoman for Milwaukee's Muslim community to media outlets, government officials, interfaith leaders, academic institutions, hospitals, and a wide range of community groups. She also directs the new Islamic Resource Center (IRC) on the south side of Milwaukee.

\section{Measure}

The interview questions were drafted, discussed, and finalized based on a comprehensive literature review and personal experience of researchers and community leaders. The interview questions began with collecting demographic information about the participants' age, marital status, education, country of origin, age of child with disability, and disability types. The second half of the interview questions consisted of open-ended questions that provided a framework of responses related to their lived experience being caregivers of children with disabilities. Examples of the open-ended questions included: "Compared to broader U. S society, how do you think the Muslim community perceived disability that are very visible?" "Have you or the person that you care for experienced prejudice, negative remarks, or discrimination because of your faith, culture or national origin?" and "What are the biggest challenges you have faced as a caregiver of an individual with disability?" The set of questions sought to develop a comprehensive picture as to how cultural and religious background as well as immigrant status and gender altogether shaped the experiences and needs of the caregivers.

\section{Data Collection Methods}

Data were collected using semi-structured, face-to-face interviews between November 2018 and December 2019. Each interview lasted about 60-90 minutes. The semi-structured 
interview questions were derived from comprehensive literature review and the personal experience of the researchers and the community leaders who closely engage with the target population. This type of in-depth interview is utilized substantially by different healthcare professionals and researchers in the fields of disability critical studies and cultural studies as it allows researchers to explore the respondents systematically and comprehensively, and at the same time, keeping the interview focused on the research agenda (Jamshed, 2014).

\section{Data Collection Procedures}

A purposive sampling (Houser, 2019) was employed to select appropriate participants for this study using two types of recruitment strategies: (a) a multigenerational snowball sampling approach by sending out an online survey link to individuals that might have been interested and met the study criteria, (b) posting the study recruitment flyers at the Muslim community resource centers, mosques, and their websites that serve the Muslim and Arab populations in the region. All interviews were conducted in private settings chosen by the participants. The data material was digitally recorded and later transcribed verbatim by the researchers. The digital records of the interviews were destroyed (as planned) as soon as the interview was transcribed for data analysis.

\section{Consent Process}

This study was approved by the university Institutional Review Board (IRB) (HR -3578).

Before conducting the interview, the purpose, the research design of the study, and the voluntary nature of the participation were explained. The participants were assured that no names or other identifying information would be used when discussing or reporting data. No incentive was provided to participants.

\section{Data Analysis}


The data were thematically analyzed to identify patterns or major themes and to reflect the experiences of participants (Sundler et al., 2019). Thematic analysis was conducted by following the six phases outlined by Braun and Clark (2008). The phases flow in sequence as followed, (1) the data set were being familiarized through several readings to gain a more global sense of the participants' experience, (2) preliminary codes were generated across the entire data set, (3) the potential themes were developed through collating the codes independently. The discussion continued until agreement was reached among the researchers regarding the potential themes. Themes were then reviewed and checked to see if they were consistent with the coded extracts and the entire data set, (5) the themes were named and defined with ongoing refinement, and finally (6) the extracts were appropriately selected and the analysis and results were written up.

\section{Results}

The overall analysis of the qualitative data produced the following four themes based on the participants' experiences of being mothers of their children with disabilities: Caregiving sentiments, challenges and disparity, sources of fortitude, and needs and wishes (insert Table 3).

\section{Caregiving Sentiments}

Three subthemes emerged from this theme where participants communicated their attitudes toward caregiving. They touched on their responsibility in being the sole caregiver, the religious value they attach to caregiving, their acculturation as immigrants, and their emotional well-being.

\section{Sole Caregiver}

One participant expressed the need to be the sole caregiver for her child with disability but at the same time did not realize there are other resources that are beneficial to her child, 
I feel the sole responsibility to take her back and forth to her classes, provide her with her medical care, get her what she needs, hospital, you know, doctor visits, tests, whatever needs to be done. My sole responsibility. ... I just presumed, oh, my culture, I'm taking care of her. I don't need any help. But [I] did not realize there was help - financial and things like that, regarding her.

Many participants who reported that they are sole caregivers of the person with disability also noted that they were unaware of the external sources and help provided by state or community institutions. While such external support was cherished, within the family mothers expressed they would be the caregivers until the duty was passed to their spouses or other children, if any, after their death. In this sense, the question of who would take care next was a major concern for others who are divorced or have no other children. It was a lifetime responsibility and mainly was based on the role of women as the natural caregiver, as pointed out by another participant:

I just think that women are just more nurturing, understanding, and caring, ... his father is still alive .... but he wasn't able to [or] couldn't care for our sons so both children returned to me.Women were highly conscious of this ascribed role and acting out of it or speaking against it would yield negative reactions from the community. While they reflected on the feeling of loneliness in taking care of the children with disability, they did not express any desire or opinion to challenge this role, as it is perceived as part of motherhood and religious test and task.

\section{Religious Value/Integrative Care}

Participants abide by religious values while caring for their children. One participant emphasized that, "to be caring and to be merciful. That issue of mercy as a trope or as a frame is something that compels you to do more". She saw herself being a special parent: 
Because God gave me a child and not anyone could just take care of that kind of child. So, God chose me to take care of that kind of child, ... Not everyone can take care of special children. Those parents are very special. ... you think, "I am special because I have a special needs child" and then your world is great.

Such views are not uncommon and are uttered with confidence that disability is a "test" from God both for the person who has it and for their caregiver. Such religious beliefs provided source for hope, patience, and "mercy." Religion, in this sense, was a major reference for rationalization and seeking (or not seeking) treatment. Other than religious and cultural views, personal conceptions shaped the sort of care or medical support mothers used. A participant asserted the importance of using integrative care, I am very against traditional, or conventional, medication because I know the side effects. [They may] cure something but the cure could hurt something else. Right now I do not take any medication and I wish that my kids did not take any medication; if anything happens I want to help them and I want them to help themselves to do something other than just taking medication.

\section{Second Generation}

Participants observed openness among younger generations within the community in terms of their attitudes towards disability issues. They also pushed for having younger imams (clergy) and religious leaders, who would presumably be better at relating to the youth, to build awareness and educate the community. As one participant put it, And now they are better in many levels, they have new imams, ... young imams, second generation imams [who] understand the situation more, so I think we are starting to understand the situation... [regarding] how to deal with the young[er] generation.

\section{Emotional Well-Being}


In terms of caregiver's emotional well-being, they experienced mixed feelings of guilt and other mental health concerns. As this participant expressed, Unfortunately, we didn't know what he was going through and that he... [was] developing mental illness. We started to feel like we had failed as parents in raising him. Another participant also articulated a similar emotional reaction, I think in the beginning when I first found out ... I was [experiencing] a lot of depression and anxiety and I was on anxiety medication ... I was just in shock because we didn't really realize she had... [communicative disorders] until 6 months after she even left the hospital.

As the above quotations demonstrate, initial anxiety is caused by lack of knowledge about the disability and the sort of care, and denial phases. During this initial stage, expectedly, discovering the disability and yet difficulty in accepting it results in depression and anxiety. Yet, much of the damage in emotional well-being is noted to be due to the stigma and the perceived stigma in the community. Particularly, in the cases of mental disability, some mothers expressed that they still hide the situation even from their own relatives such as the parents in-law. The feeling of shame, the risk of damaging the reputation of family name, and pressure due to the fear of repelling suitors for other members of the family lead mothers to hide the disability from others outside the family. Apart from these, a few single mothers expressed how mentally weary they feel because of being the sole caregivers.

\section{Challenges and Disparity}

Five subthemes emerged in response to questions about challenges and disparity that the mothers experience while caring for their children: Uncertainty in caregiving, limitations in 
resources and knowledge, accessibility and inclusivity issues, gender role and intersectionality, and stigma.

\section{Uncertainty in Caregiving}

This subtheme includes unpredictability of the child's activities in the public. Participants reported how their life is different caring for a child with disability. A participant reported,

I think what people don't realize is life is completely different when you have a family member with a disability. Normal things [like] going to a restaurant or going to the grocery store or taking vacation isn't necessarily possible all the time. Everything is very calculated, and we like to stick to routine as much as possible. So, going just randomly to go meet friends at a restaurant in a large group and just wait 20-30 minutes for your food is just not going to happen for our family.

With all the participants that have more than one child, they shared the trails of juggling between caring for a child with a disability and those without disability. As one participant pointed out, I think my challenges were caring for both my eldest child with disability and my second one, who was without disability but who had her set of issues so between the two of them it seemed like I was just in and out of hospitals. I would try and go to the library to keep my daughter stimulated and he just couldn't sit still. I would turn around one second and then the next second the librarian would be saying get your son he's throwing all the books of the shelf he's climbing the shelves ... and at home he did the same thing.... I kept putting things higher, but he just kept climbing so it was just hard to do anything. These kinds of complexities in one's family situation and lack of awareness discouraged caregivers from participating in social life and attending community events including the Friday gathering at the mosque. Mothers gave examples of certain incidents which led them to give up 
attending the community prayers. Some children with disabilities require that the mothers constantly accompany their children, thus they are denied from places or activities that require the mother and child to be apart even for a short period. The fear of probable situations in which children with disabilities may be subjected to unwelcoming reactions in a social setting result in the caregiver deciding to abandon plans for attending altogether. Many mothers suggested that educating community members of these issues and a general public awareness should be an important part of the solution for the caregivers to feel welcome and for creating safe spaces for their children.

\section{Limitation in Resources and Knowledge}

As to facing the impediment in accessing resources, participants commented on the benefits of having medical insurance but noted the difficulties of obtaining additional resources to meet the child's needs while working full time.

One mother who is employed full time commented, I think one of the biggest challenges for me was [logistical] ..., my friend [who] is a speech therapist ...I was actually paying her out of pocket because I wanted extra speech therapy [sessions] where [she] could come to the house. It was hard for me [to use a therapist in a center which has regular business hours]. [Previously] I used to use a center and I had signed [my daughter]...to see a speech therapist.... This is out of school to get extra speech therapy [but] it was just too hard for me to go from work, to pick her up, to go all the way to another town. They closed at 5 so it just didn't work out for me. Moreover, because of being the first-generation immigrants to this country, participants felt they lacked adequate knowledge regarding available services in order to provide the best care for their children. One participant stated, 
I don't want to tell people, the thing is, I don't know... resources. If there is something good for my son, then I am able to help more....[but] I don't know, so I don't tell people....about my son.

As the above quote shows, the lack of knowledge is also related to the tendency to hide the disability within the family. Immigrant communities mainly seek and receive support within their own local and ethnic communities as they become integrated into and dependent upon its social network. In many cases families do not want to share about the disability within their household with others in the community, which in turn makes it difficult for them to learn about and access the resources and services that might be available. This is particularly the case with many first-generation immigrants, where barriers are built due to cultural beliefs and social taboos. Since they fear being stigmatized by the community, they prefer to keep the information about disability a secret even if it means they will deprive themselves of any opportunities that may help their situation. Here is a sentiment expressed by a participant:

Not knowing what or how to [ask for help] ....is new. You need to get a grip on what it is and what it needs. That's really the challenge to me. I can't say that there is a lack of resources.... [Perhaps] I need to know how to ask for that or to know what's available. Similarly, mothers who are now aware of the support they can receive from different sources reflected on the earlier experiences until they somehow discovered the variety of services available to them. As to the resources and services, they mostly spoke about the difficulties in finding programs in the local area that would cater to their special needs. Mothers commonly addressed the lack of services in respite care, day programs for fun activities and for skill-building, and programs where people with disability can work or volunteer.

\section{Accessibility and Inclusivity Issues}


Participants encounter accessibility and inclusivity issues while caring for their children.

It involves mosques not being accessible for extraordinary situations because of inflexible attitudes regarding behavior and gender roles. One participant described the experience as below: Taking him to the mosque was a challenge. When he was younger it was okay aside from not being able to sit right, but then the older he got, I couldn't take him to the women's section anymore ... I couldn't even see him in the men's section ... it was just extremely difficult to be able to be there with him.

The codes and rules in religious and cultural settings intimidate mothers and cause

feelings of exclusion. A similar experience was reported by another mother whose child was disturbed by the loud prayer/recitation in the mosque and wasn't able to sit still, which created a distraction to another person present there. While mothers acknowledge that there are certain etiquette and expectations in such places, they also highlight the inclusive message of religion. The exclusion is not peculiar to the religious or cultural community, and it is experienced in a wide range of settings, including in schools and social events. Another participant discussed the lack of inclusivity in the community that leads to social isolation,

Some people ask questions or shrug you off like you do not belong here ... even for his high school graduation he doesn't want to go. ... he keeps to himself, and when I think about why he keeps to himself I think that maybe he has some experience of [being not wanted] in his life which [is why he] doesn't want to share anything. Despite the prevalence of such cases, most mothers noted that things are slowly changing and there are new trends visible in their communities; particularly as the generation shifts takes place and younger, more educated leaders are emerging who are more aware of the needs of people with disabilities which surfaced in the next main theme - Source of Fortitude. 


\section{Gender Role and Intersectionality}

Gender disparity is present in how the Muslim community views traditions and customs with regard to women's roles and functions. Participants shared their thoughts on inequity and disparity in many areas of their lives such as prospects for finding a suitor, the ability to wear certain clothes and the standards of modesty, and the additional responsibilities assumed in the role of being a mother, a caregiver and an advocate.

One participant described her advocacy effort when she realized her daughter's IEP didn't paint the right picture about her,

... based on what they assessed her on and what we saw at home it was completely different ... So I actually started videotaping her at home to show the IEP... I actually talked to the director I was a little bit upset about certain things that they had put in there and you have to be really on top of them ... I'm the mom and I know my daughter and I see what she does.

Intersectionality also made it possible to see how people with different social identities were marginalized. One participant noted about the experience of discrimination simply because of who she is:

...you're discriminated against for being a minority, you're discriminated against for being a woman, you're discriminated against for being a Muslim. Unfortunately, that's...three strikes for my daughter. It is something that is definitely on the forefront of our minds.

\section{Stigma}

Lastly, within the community, participants shared their experiences of discrimination for having a child with disability. Particularly, the attitudes regarding the martial prospects, the fear 
that the disability will contaminate the family gene and impact future generations. Such beliefs contribute to the practice of being secretive about the presence of person/s with mental illness or disability in the family.

I really don't want anyone to know about my daughter. I was not happy at all to learn that she [shared her diagnosis] ...For me, I don't want anybody to know. ... this is part of our culture and we are very sensitive to these illnesses, it's more than physical. If it's physical like being diabetic, we're ok, but emotional and psychological issues are different. In the end I want her to marry a good person, sometimes people in the community talk [bad, hence the desire to keep it a secret].

Similarly, another participant pointed out, I think mental illness is more stigmatized than physical disabilities. It's like corporate punishment. If one has a mental illness, then maybe the whole family has one too. So, we are not open to talking about it. So, if it is a female suffering from depression, they will be hiding that and not seek help because of the stigma and because [otherwise] they think they won't be able to find a marriage partner or something like that.

\section{Sources of Fortitude}

Three subthemes emerged from this theme regarding where they find strengths while experiencing challenges: health allied professionals, communities, and personal.

\section{Health Allied Professionals}

Participants reported that having the connection with a team of health allied professionals was helpful. As one participant stated, I always found the teachers, therapists, physical therapists and the speech therapists - 
everyone we had to work with - [very helpful and] kind; [they] were really trying to work with him and accommodate him.

Another participant also shared a similar experience,

Alopecia doctor ... was helpful .... She did see a psychologist at one point when her younger sister started passing her in school and [even received her] driver's license....

And then I sat with that psychologist and she said every time one of her younger siblings reached a milestone that she was never going to reach, that was going to be a difficult time. So, seeing that psychologist was good. Teachers were [a] great resource, I think they provide a lot of [useful] information, including ... [that] when she turned 18, I should take legal guardianship on her. I would have never known that on my own....

\section{Communities}

Participants also found strengths through their connections in the Muslim community and community in general. In terms of support within the Muslim community, one participant noted the excellent work by one Muslim non-profit group "Muslims Understanding and Helping Special Education Needs" (MUHSEN) which supports families with children with disability, I've had help from some friends from the Muslim community that have given me tips ...her daughter has autism and she has recommended things for my daughter... I'd [also] given her recommendations ... the younger generation has become a little bit more knowledgeable and understanding ... one of the mosques here [has] just implemented [programs by MUHSEN] so that's just amazing.... One participant appreciated her non-Muslim co-workers who were sympathetic,

...they were so supportive and make whatever schedule work, [they said,] "we are here to support you and your family" .... they really made it work from a scheduling aspect.... I 
work with a research scientist and he stayed up all night researching and tried to give me an answer to why my children have autism .... To me that was really emotional and helpful from a support aspect even someone just [trying to] understand ...

\section{Prayers/Faith}

Personal strengths stemming from non-medical aspects included religious beliefs and prayers, and managing the symptoms using integrative care. Especially, religious beliefs were of vital importance to many who relied on them for rationalization to find an answer to the question "why," and for finding patience, and even for feeling special. Additionally, in moments of an emotional crisis, many said to resort to prayers and to remember God. One participant expressed her belief that the strengths were due to her faith and prayers,

It was our faith that drove us to do the best that we could with [our son] and give him the opportunities that we could but it really was early on deciding that he was going to experience things just like the other kids. We actually had a conversation about it [like] should he go bike riding or should he not.... And then we just said you know what? We are going to pray for his safety, and we are going to take every precaution that we can but he should go bike riding.

Almost all of the participants expressed that the Islamic perspective on people with disabilities is very supportive. However, cultural attitudes of some people often create the stigma which is neither religious nor humane. It hurts the entire family in so many ways that it is nearly impossible to imagine it for someone who has not had that experience. This participant pointed out, ...what is historically known in the Muslim community is [that] it's not necessarily religion, it's more cultural ... [where the] stigma about people with disabilities [exists]... 
when we look at the religion itself, and any religion, [it] talks about embracing these special individuals with needs.

\section{Needs and Wishes}

Lastly, three subthemes arose in participants' needs and wishes even as they embraced the support that they already received, managing their personal challenges, and advocate for a culturally responsive resource.

\section{Quality Support}

Due to their particular cultural and religious values, participants felt that to add to the quality of support there should be resources that cater to those religious needs of the community. This may include inviting a Muslim leader / scholar to raise awareness of disability in the community and the religious imperative of insuring equal treatment and support for such individuals. One participant said that,

I always thought that was a wonderful idea, to have a Muslim speaker come out who speaks good English, and can articulate more things about Muslims because they're going to see our children fasting during Ramadan, praying during school ... and having the speakers come and talk to the schools. And whether it's educating about Islam or even somebody once mentioned educating [my son's] class about his impairment, you know? The more they know [the better].

Another participant mentioned the need of quality respite care,

I wish that there really was some formal form of respite care where ... once a week, I am going to have an experienced caregiver, not just a babysitter ... [who] is skilled, with these kinds of kids, [but] that was not available. 
Regarding the health care support, some mothers explained that the setting for some types of treatment or therapy is unsuitable for their needs; this includes cases in which behavioral therapy is applied in clinics whereas the situation requires the setting to be the home environment so that the person can be observed in his/her familiar environment and faced with actual circumstances.

\section{Personal Changes}

Participants expressed the need to learn to ask for help or use different resources to provide the best care to the person for whom they were caring. Some of the stress and anxiety could be relieved if an outside caregiver was available to help.

I think sometimes I really should look for some sort of help in that respect, somebody who is younger [than I am]. If I should try and get someone who is more patient who is younger maybe who would be able to accomplish some of these tasks.

Another participant shared a similar viewpoint, When I had a lot of kids and they were younger, there were times where it was emotionally draining. And mostly because I wanted to keep [my son's] responsibilities on me rather than having his siblings do more, which retrospectively I shouldn't have done. I should have given them responsibilities so they could help out ... so I didn't [get fatigue and exhaustion] ... so I took the brunt of the work.

\section{Culturally Responsive Resources}

Participants expressed the need to have more healthcare professionals to acquire knowledge of where disability and religion intersect, so as to be able to provide support and resources accordingly. Professionals will be better at navigating the needs that arise from the combination of those factors. One participant expressed, 
I think that healthcare providers and teachers and [people] that work with special needs, may [need to] educate themselves ... because there are more and more kids being diagnosed with autism and they're Muslim ... maybe [they need to know] about the religion of Islam and how our values are different regarding transitioning into daycare and adult care facilities and things like that.

The demand for familiarity with cultural and religious values indicates how these values intersect with the treatment received apart from how disability is perceived.

\section{Discussion}

Williamson and Perkins (2014) pointed out that with the prevalence of patriarchal structures of relationships in many Muslim cultures, Muslim mothers tend to take on the caregiver role when there is a need in the family. The participants in this study also felt responsible for being the sole caregivers to their children with disabilities. As women and mothers, they were seen to be "naturally good" in caring for children. Although participants expressed their satisfaction in their caregiving role and connected it with their spiritual fulfillment and their sense of love, they also felt inadequate, regretful, and distressed especially during the years when their children were younger. The anxiety they felt stemmed from various reasons such as the feeling of insufficiency, other difficulties intersecting with being an immigrant and/or minority, difficulties in balancing their lives and responsibilities, stigma associated with disability and its implications, and community attitudes. Similarly, Nahal et al (2017) reported caregivers' distress among women as they provided care for their children with disability. Ahmad and Khan (2018) noted the decreasing well-being among caregivers of children with disabilities. In addition, caregiving is perceived as a religious duty which obliges mothers not only to take care of the family members with disability but also to do it without a 
sign of complaint (Othman, 2020). Mothers emphatically noted that hiring someone to be the primary caregiver for their children was not an option for them as they were seen to be sufficient for the job no matter the circumstances.

Rather than delegating their caregiving responsibilities to others or formal caregivers, the mothers seek communal supports in disability inclusion. Research has shown that caregivers are not only confronted with challenges in emotional well-being, they make use of their frustration to impact their advocacy in accessibility of resources and awareness of disability issues (Mathias et al., 2019; Miller et al., 2017). The Muslim immigrant community in the Midwest region constitutes a diverse local group with people coming from different countries. Community Muslim organizations and institutions with a number of services and activities play an important role in forming a society around the common identity of being Muslim. Interviewers in this study, as members of this community, told their experiences with regard to these institutions and attitudes they face in these social circles. While some parents did not discern any difference between Muslim community and other religious communities in terms of the approach to disability, others stressed the necessity for more awareness, education, accessibility, and inclusiveness that should be improved in Muslim community and organizations (Othman, 2020). In the Muslim culture, chronic illness and medical conditions that limit the daily functioning are believed to be a test of faith, and the family is expected to be patient with the situation (Arabiat et al., 2013). Cultural interpretations significantly matter in the interpretation of disability and in the degree treatment and support is received. Interpretations such as "evil eye" may result in delays or negligence of the medical treatment due to denial of the disease/impairment as a biological/medical condition (Othman, 2020). Such conceptions may result in communication failures and discrepancy among the family. For example, one mother 
narrated her struggle for her child to receive therapy which is opposed by elderly family members who thought "there was nothing wrong." Thus, especially situations which require therapy or psychological support lead to dispute and disregard. Mothers' expectation from religious leaders and Imams to preach in favor of medical and professional treatment is a significant indicator of the role of these institutions to shape and reshape concepts. The stigmatization influences how the family takes care of the child. Most often, parents are likely to "hide" the medical conditions and to avoid associated discrimination and prejudice from the society (Al-Aoufi, Al-Zyoud, \&Shahminan, 2012).

An important distinction is created between Islamic perspectives on people with disabilities and the stigma created by the society. Most of the mothers are devout followers of Islam, and they are strongly attached to their religious community. As Al-Aoufi et al (2012) assert, Islamic value showed positive attitude towards individuals with medical conditions that limit their daily functioning. While the participants report the negative attitudes they faced in a Mosque or religious center, they also refer to the supportive messages in Islam by referring to verses, examples from the Prophet's life or from the history of Islam. In addition, they find comfort in faith and prayer. Thus, they attribute the deficiencies and stigma to cultural attitudes of people. This clear distinction is also seen in their invitation to Imams and religious scholars to create awareness and educate the community.

Although there is a sense of accomplishment among women for being the caregivers of their children, the participants also mentioned the challenges such as unpredictability, limited resources when working full time, lack of knowledge of options due to being an immigrant, barriers in accessing resources available at the mosque because of gender issues, and the stigma 
regarding disability. Heer et al $(2012,2015)$ shared similar evidence for the issues encountered by caregivers.

Among these concerns, gender constitutes a central factor that also shapes other significant conditions. The domestic role attributed them as the primary caregiver with expected full devotion restricts them from other aspects of life including social interaction. The ethnic and religious community centers and institutions which are their main socialization settings may make them feel excluded. Facing such attitude, they do not communicate their disappointment or demands to the people in charge directly. As women, the imposed position to comply increases their anxiety. In addition, they share the concerns of marital prospect not only for daughters, if any, with disability but also for their daughters without disability but still unfavorable due to the stigma associated with family.

\section{Conclusion}

This study provided a unique perspective on the intersection of gender with culture, religion, and immigrant status for the mothers of a child with disability. It revealed the gendered stigma with mental illness, intersectionality, and the physical space that separate the mother and the son with disability. It also asserted the needs of inclusion and awareness in mosques while navigating the gender issues. Despite the challenges that the caregivers experience, their source of strengths stem from their faith and hope. Their strong belief in the Islamic value and Qu'ran provide strengths for the community to advocate for accessibility and inclusion, especially with the leadership of the second-generation Muslims clergy and religious leaders. 


\section{Reference}

Abu-Ras, W., Suárez, Z. E., \& Abu-Bader, S. (2018). Muslim Americans' safety and well-being in the wake of Trump: A public health and social justice crisis. American Journal of Orthopsychiatry, 88(5), 503-515. https://doi.org/10.1037/ort0000321

Ahmad, T., \& Khan, M. I. (2018). Caregiver distress: A comparative study. Indian Journal of Health and Wellbeing, 9(1), 93-96.

Al-Aoufi, H., Al-Zyoud, N., \& Shahminan, N. (2012). Islam and the cultural conceptualization of disability. International Journal of Adolescence and Youth, 17(4), 205-219. https://doi.org/10.1080/02673843.2011.649565

Al-Krenawi, A., Graham, J. R., \& Al Gharaibeh, F. (2011). The impact of intellectual disability, caregiver burden, family functioning, marital quality, and sense of coherence. Disability \& Society, 26(2), 139-150. https://doi.org/10.1080/09687599.2011.543861

Aloud, N., \& Rathur, A. (2009). Factors affecting attitudes toward seeking and using formal mental health and psychological services among Arab Muslim populations. Journal of Muslim Mental Health, 4(2), 79-103. https://doi.org/10.1080/15564900802487675

Arabiat, D. H., Al Jabery, M., Abdelkader, R. H., \& Mahadeen, A. (2013). Jordanian mothers' beliefs about the causes of cancer in their children and their impact on the maternal role. Journal of Transcultural Nursing, 24(3), 246-253.

https://doi.org/10.1177/1043659613481808

Bazzano, A., Wolfe, C., Zylowska, L., Wang, S., Schuster, E., Barrett, C., \& Lehrer, D. (2015). Mindfulness Based Stress Reduction (MBSR) for parents and caregivers of individuals with developmental disabilities: A community-based approach. Journal of Child \& Family Studies, 24(2), 298-308. https://doi.org/10.1007/s10826-013-9836-9 
Braun, V., \& Clarke, V. (2008). Using thematic analysis in psychology. Qualitative Research in Psychology, 3(2), 77 - 101.

Budhwani, H., \& Hearld, K. R. (2017). Muslim women's experiences with stigma, abuse, and depression: Results of a sample study conducted in the United States. Journal of Women's Health, 26(5), 435-441. https://doi.org/10.1089/jwh.2016.5886

Ciftci, A., Jones, N., \& Corrigan, P. W. (2012). Mental health stigma in the Muslim community. Journal of Muslim Mental Health, 7(1), 17-32.

Conway, T. D. (2014). Cross-cultural Dialogue on the Virtues the Contribution of Fethullah Gülen. Germany: Springer International Publishing.

del Río-Lozano, M., García-Calvente, M. del M., Marcos-Marcos, J., Entrena-Durán, F., \& Maroto-Navarro, G. (2013). Gender identity in informal care: Impact on health in Spanish caregivers. Qualitative Health Research, 23(11), 1506-1520. https://doi.org/10.1177/1049732313507144

Diken, I. H. (2006). Turkish mothers' interpretations of the disability of their children with mental retardation. International Journal of Special Education, 21(2), 8-17.

Family Caregiver Alliance. (2019, December). Caregiver statistics: Work and caregiving. https://www.caregiver.org/caregiver-statistics-work-and-caregiving

Haskell, R., Graham, K., Bernards, S., Flynn, A., \& Wells, S. (2016). Service user and family member perspectives on services for mental health, substance use/addiction, and violence: A qualitative study of their goals, experiences, and recommendations. International Journal of Mental Health Systems, 10(9), 1-14. doi:10.1186/s13033-0160040-3

Heer, K., Larkin, M., \& Rose, J. (2015). The experiences of British south Asian carers caring for 
a child with developmental disabilities in the UK. Tizard Learning Disability Review, $20(4), 228-238$.

Heer, K., Larkin, M., Burchess, I., \& Rose, J. (2012). The cultural context of care-giving: Qualitative accounts from south asian parents who care for a child with intellectual disabilities in the UK. Advances in Mental Health and Intellectual Disabilities, 6(4), 179191. http://dx.doi.org/10.1108/20441281211236580

Hooda, S., \& Gupta, A. (2017). Mental health of primary caregivers with children having intellectual disability. Indian Journal of Health \& Wellbeing, 8(12), 1570-1573.

Houser, R. (2019). Counseling and educational research: evaluation and application (4th ed.). Sage Publications.

Jamshed, S. (2014). Qualitative research method - interviewing and observation. Journal of Basic Clinical Pharmacy, 5(4), 87- 88. http://doi.org/10.4103/0976-0105.141942

Kayadjanian, N., Schwartz, L., Farrar, E., Comtois, K. A., \& Strong, T. V. (2018). High levels of caregiver burden in Prader-Willi syndrome. PLoS ONE, 13(3).

Kim, H., Sefcik, J. S., \& Bradway, C. (2017). Characteristics of qualitative descriptive studies: A systematic review. Research in Nursing \& Health, 40(1), 23-42. https://doi.org/10.1002/nur.21768

Koehler, A., Fagnano, M., Montes, G., \& Halterman, J. (2014). Elevated burden for caregivers of children with persistent asthma and a developmental disability. Maternal \& Child Health Journal, 18(9), 2080-2088. https://doi.org/10.1007/s10995-014-1455-6

Litzelman, K., Witt, W. P., Gangnon, R. E., Nieto, F. J., Engelman, C. D., Mailick, M. R., \& Skinner, H. G. (2014). Association between informal caregiving and cellular aging in the Survey of the health of Wisconsin: The role of caregiving characteristics, stress, and 
strain. American Journal of Epidemiology, 179, 1340-1352. doi:10.1093/aje/kwu066

Mathias, K., Kermode, M., San Sebastian, M., Davar, B., \& Goicolea, I. (2019). An asymmetric burden: Experiences of men and women as caregivers of people with psycho-social disabilities in rural North India. Transcultural Psychiatry, 56(1), 76-102. https://doi.org/10.1177/1363461518792728

Miller, K., Sukhera, J., Lynch, J., \& Wardrop, N. (2017). Voices unheard: Exploring the caregiver experience for caregivers of emerging adults with mental illness. Families in Society, 98(4), 310-318. https://doi.org/10.1606/1044-3894.2017.98.36

Mohamed, B. (2018). New estimates show U.S. Muslim population continues to grow. Pew Research Center. Retrieved from https://www.pewresearch.org/fact$\operatorname{tank} / 2018 / 01 / 03 /$ new-estimates-show-u-s-muslim-population-continues-to-grow/

Mohamed Madi, S., Mandy, A., \& Aranda, K. (2019). The perception of disability among mothers living with a child with cerebral palsy in Saudi Arabia. Global Qualitative Nursing Research, 6, 1-11.

Nahal, M. S. H., Wigert, H., Imam, A., \& Axelsson, Å. B. (2017). From feeling broken to looking beyond broken: Palestinian mothers' experiences of having a child with spina bifida. Journal of Family Nursing, 23(2), 226-251. https://doi.org/10.1177/1074840717697436

Neufeld, A., Harrison, M.J., Stewart, M.J., Hughes, K.D., \& Spitzer, D. (2002). Immigrant women: making connections to community resources for support in family caregiving. Qualitative Health Research, 12(6), 751-768.

Othman, E. (2020). Disabilities project initial report. AMWRRI Digital Archive on Disability. https://amwrri.org/cms/s/arab-and-muslim-womens-research-and-resource- 
institute/page/reports.

Pharr, J. R., Francis, C. D., Terry, C., \& Clark, M. C. (2014). Culture, caregiving, and health: Exploring the influence of culture on family caregiver experiences. ISRN Public Health, 1-8. https://doi.org/10.1155/2014/689826

Pinquart, M., \& Sörensen, S. (2006). Gender differences in caregiver stressors, social resources, and health: An updated meta-analysis. The Journals of Gerontology: Series B: Psychological Sciences and Social Sciences, 61(1), 33-45. https://doi.org/10.1093/geronb/61.1.P33

Reinhart, A. K. (2005). Origin of Islamic ethics: Foundations and constructions. In William Schweiker (Ed.), The Blackwell companion to religious ethics (pp. 244-253). London: Blackwell.

Saria, M., Courchesne, N., Evangelista, L., Carter, J., MacManus, D., Gorman, M., Nyamathi, A., Phillips, L., Piccioni, D., Kesari, S., Maliski, S., Saria, M. G., MacManus, D. A., Gorman, M. K., Nyamathi, A. M., \& Phillips, L. R. (2017). Cognitive dysfunction in patients with brain metastases: influences on caregiver resilience and coping. Supportive Care in Cancer, 25(4), 1247-1256.

Sundler, A. J., Lindberg, E., Nilsson, C., \& Palmér, L. (2019). Qualitative thematic analysis based on descriptive phenomenology. Nursing Open, 6(3), 733-739. http://dx.doi.org/10.1002/nop2.275

Swaine, J. G., Dababnah, S., Parish, S. L., \& Luken, K. (2013). Family caregivers' perspectives on barriers and facilitators of cervical and breast cancer screening for women with intellectual disability. Intellectual and Developmental Disabilities, 51(1), 62-73.

Wiener, J., Gould, E., Shuman, S., Kaur, R., \& Ignaczak, M. \& Maslow, K. (2016). Examining 
models of dementia care: Final Report. Prepared for the Office of the Assistant Secretary for Planning and Evaluation. Washington, DC: U.S. Department of Health and Human Services.

Williamson, H. J., \& Perkins, E. A. (2014). Family caregivers of adults with intellectual and developmental disabilities: Outcomes associated with U.S. services and supports. Intellectual and Developmental Disabilities, 52(2), 147-59. 


\section{MUSLIM MOTHERS OF CHILDREN WITH DISABILITIES}

Table 1

Participants Characteristics $(N=11)$

\begin{tabular}{|c|c|c|}
\hline Characteristics & $\mathrm{N}$ & $\%$ \\
\hline \multicolumn{3}{|l|}{ Age (category) } \\
\hline $30-45$ & 4 & 36.4 \\
\hline $46-60$ & 3 & 27.2 \\
\hline 61 and older & 4 & 36.4 \\
\hline \multicolumn{3}{|l|}{ Marital status } \\
\hline Married & 10 & 90.9 \\
\hline Single & 1 & 9.1 \\
\hline \multicolumn{3}{|l|}{ Country of origin } \\
\hline United States & 2 & 18.2 \\
\hline Others & 9 & 81.8 \\
\hline \multicolumn{3}{|l|}{ Employment status } \\
\hline Full time & 7 & 63.6 \\
\hline Retired & 1 & 9.1 \\
\hline Homemaker & 3 & 27.3 \\
\hline Educational level & & \\
\hline
\end{tabular}


MUSLIM MOTHERS OF CHILDREN WITH DISABILITIES

\begin{tabular}{|l|l|l|}
\hline High school or less & 1 & 9.1 \\
\hline Associate/bachelor's degree & 5 & 45.4 \\
\hline Master's degree & 5 & 45.5 \\
\hline
\end{tabular}




\section{MUSLIM MOTHERS OF CHILDREN WITH DISABILITIES}

Table 2

Characteristics of Individuals with Disabilities that the Participants Care For $(N=12)$

\begin{tabular}{|c|c|c|}
\hline Characteristics & $\mathrm{N}$ & $\%$ \\
\hline \multicolumn{3}{|l|}{ Disability Domain* } \\
\hline Communication & 2 & 16.7 \\
\hline Physical & 3 & 25.0 \\
\hline Mental & 7 & 58.3 \\
\hline \multicolumn{3}{|l|}{ Age (category) } \\
\hline School age & 3 & 25.0 \\
\hline $18+$ & 9 & 75.0 \\
\hline \multicolumn{3}{|l|}{ Gender } \\
\hline Female & 6 & 50.0 \\
\hline Male & 6 & 50.0 \\
\hline
\end{tabular}

*Definition according to U.S Census Bureau (Taylor, 2018) 
MUSLIM MOTHERS OF CHILDREN WITH DISABILITIES

Table 3

Participants' Experiences of Being Mothers of The Children with Disabilities

\begin{tabular}{|l|l|}
\hline Theme & Subtheme \\
\hline Caregiving Sentiments & Sole Caregiver \\
\hline & Religion Value/Integrative Care \\
\hline & Second Generation \\
\hline Challenging and Disparity & Emotional Well-Being \\
\hline & Uncertainty in Caregiving \\
\hline & Limitation in Resources and Knowledge \\
\hline Sources of Fortitude & Accessibility and Inclusivity Issues \\
\hline & Gender Role and Intersectionality \\
\hline & Stigma \\
\hline & Health Allied Professionals \\
\hline & Communities \\
\hline & Prayers/Faith \\
\hline & \\
\hline & \\
\hline & \\
\hline & \\
\hline & \\
\hline & \\
\hline & \\
\hline & \\
\hline & \\
\hline & \\
\hline & \\
\hline
\end{tabular}


MUSLIM MOTHERS OF CHILDREN WITH DISABILITIES 